\title{
Antropología
}

\section{Espaço, liminaridade e sociabilidade: etnografia da sala do café de uma unidade hospitalar}

Space, liminarity and sociability: ethnography of the dinning room in a hospital unit

\section{Espacio, liminaridad y sociabilidad: etnografía de la sala de café de una unidad hospitalaria}

\author{
Lucas Pereira de Melo (L. P. MELO) ${ }^{1}$, Maria Helena Lenardt (Ma H. LENARDT) ${ }^{2}$
}

${ }^{1}$ Doutor em Ciências. Professor do Curso de Medicina multicampi da Universidade Federal do Rio Grande do Norte (UFRN). Líder do Laboratório de Pesquisas Antropológicas em Medicina e Saúde.

${ }^{2}$ Doutora em Filosofia da Enfermagem. Professora Sênior do Programa de Pós-graduação em Enfermagem da Universidade Federal do Paraná (UFPR). Líder do Grupo Multiprofissional de Pesquisa sobre Idosos.

Cómo citar este artículo en edición digital: Melo, L.P. y Lenardt, Ma. H. (2014) Espaço, liminaridade e sociabilidade: etnografia da sala do café de uma unidade hospitalar. Cultura de los Cuidados (Edición digital) 18, 39.

Disponible en: http://dx.doi.org/10.7184/cuid.2014.39.09>

Correspondencia: Lucas Pereira de Melo. Avenida Dr. Carlindo de Souza Dantas, 540, centro, Caicó-RN, Brasil. CEP: 59300-000. Telefone para contato: 55-19-981310946. Correo electrónico: lucasenf@yahoo.com.br Recibido: 11/12/2013; Aceptado: 10/02/2014

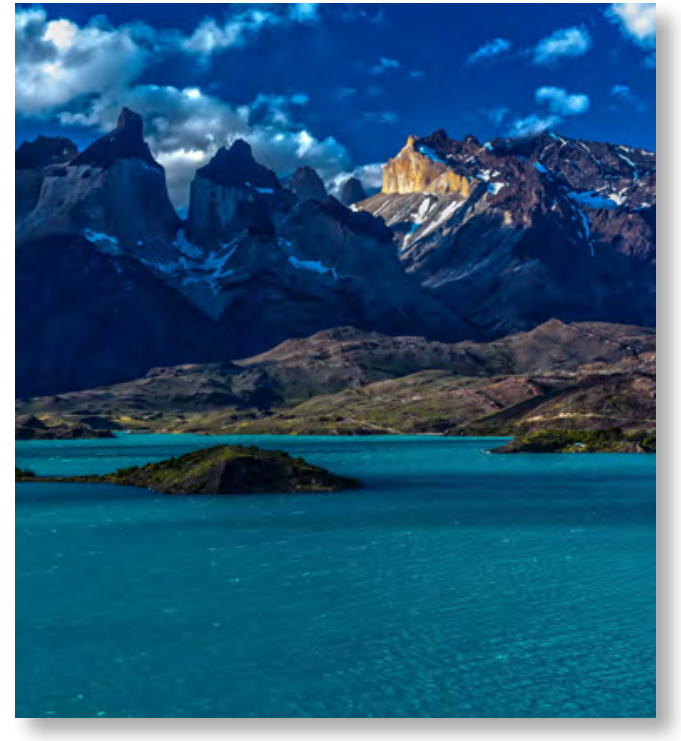

ABSTRACT

This ethnographic study aimed to interpret the structural and symbolic dimensions of the dinning room through the social interactions between the professionals of the patient team care of a Trauma Unit in an university hospital. Participant observation and semi-structured interviews were used to collect data. The analysis was performed through the development of cultural domains, taxonomic analysis and cultural themes. Four cultural domains were identified: the liminal state and the communitas; the significance of the social interactions outside the dinning room; the meaning of the closed door; and, sharing experiences at the dinning room. The cultural theme was: "the dinning room it is a place that works for everything": space, liminarity, and sociability. We conclude that the existence of physical spaces for sociability between health professionals is essential to conduct the work process, and to the workers' quality of life.

Key-words: Medical anthropology. Interpersonal relations. Patient care team. Hospital units. Ethnography. 


\section{RESUMEN}

Se trata de un estudio etnográfico cuyo objetivo consiste en interpretar las dimensiones estructurales y simbólicas del espacio físico de la sala de café de la Unidad de Trauma de un Hospital Universitario. Los datos fueron recolectados a través de observaciones participantes y entrevistas semiestructuradas $y$ analizadas en dominios, taxonomías y temas culturales. Surgieron cuatro dominios culturales: el estado liminal y la communitas; la significación de la realidad externa a la sala de café; el significado de la puerta cerrada; el intercambio de experiencias en la sala de café. El tema cultural fue: "La sala de café es el lugar que sirve para todo!" - espacio, liminaridad y sociabilidad. Llegamos a la conclusión de que la existencia de espacios físicos para sociabilidad de los profesionales es fundamental en la conducción del proceso de trabajo e para la calidad de vida de los trabajadores.

Palabras clave: Antropología médica. Relaciones interpersonales. Grupo de atención al paciente. Unidades hospitalarias. Etnografía.

\section{RESUMO}

Trata-se de estudo etnográfico, cujo objetivo foi interpretar as dimensões estruturais e simbólicas do espaço físico da copa, por meio das interações sociais entre os profissionais da equipe multiprofissional da Unidade de Trauma de um Hospital Universitário. As informações foram coletadas por meio da observação participante e entrevistas semiestruturadas e analisadas mediante a identificação de domínios, taxonomias e temas culturais. Emergiram os domínios culturais: o estado liminar e a communitas; a significação das interações sociais na realidade externa à copa; o significado da porta fechada; o compartilhar de experiências na copa. O tema cultural foi: "A copa é o lugar que serve para tudo": espaço, liminaridade e sociabilidade. Conclui-se que a existência de espaços físicos para a sociabilidade dos profissionais é fundamental para a condução do processo de trabalho e para a qualidade de vida do trabalhador.

Palavras-chave: Antropologia médica. Relações interpessoais. Equipe de assistência ao paciente. Unidades hospitalares. Etnografia.

\section{INTRODUÇÃO}

O hospital moderno é um espaço marcado pela hierarquia de poder, ordem e disciplina por meio de um processo gradual de disciplinarização e submissão originada em relações concretas e singulares. Nesse campo tomado pelo discurso e poder institucionais, as normas, as rotinas e as condutas disciplinares deslocam-se do imaginário para o concreto, construindo relações num intricado elo entre ordem e disciplina (Luz, 1986).

Sendo assim, verdadeiros campos de forças se materializam na arquitetura do hospital, na disposição espacial dos objetos e móveis, no dimensionamento dos profissionais, no equacionamento dos horários, na eleição de cores, na maneira adequada de vestir-se e comportar-se, no corpo disciplinado, no controle da sexualidade, no tom da voz, no distanciamento de emoções e sentimentalidades.

Nesse contexto, a sala do café, ou copa, compõe comumente a estrutura física de alguns setores/unidades desses serviços de saúde. Trata-se de um espaço que remete ao caráter doméstico da cozinha, por ser um local para fazer refeições, descansar e encontrar colegas de trabalho. No entanto, a sala do café como cenário integrante dos serviços de saúde (principalmente de hospitais) não tem sido foco de investigações tanto no contexto brasi- 
leiro, quanto em outros países. Ou seja, a existência da copa e das interações sociais que nela ocorrem tem sido invisibilisada ou mantida como bastidores. Dessa forma, nesta etnografia, assume-se que a copa pode assumir outros papéis e funções de caráter simbólico.

Além disso, partiu-se do pressuposto de que a instituição hospitalar, com todas as práticas e saberes que produz, está inserida em um espaço cultural que dá sentido e organiza, em última instância, os aspectos técnicos e científicos da sua produção e reprodução (Sahlins, 2003). Nessa perspectiva, os conceitos de liminaridade, antiestrutura e communitas foram empregados na análise do espaço físico da copa e das interações sociais nele engendradas pelos profissionais de saúde e outros sujeitos externos à unidade hospitalar (Turner, 2013; Van Gennep, 2008).

Entende-se por liminaridade um estado transitório ou intermediário no qual as pessoas ou, no caso em estudo, os espaços físicos são necessariamente ambíguos, escapando às redes de classificações que normalmente determinam a localização de estados e posições num contexto cultural (Turner, 2013). Esse atributo de não estar aqui nem lá, mas entre, possibilita um tipo particular de interação social que ocorre num determinado grupo - a communitas, "considerada como um 'comitatus', não-estruturado, ou rudimentarmente estruturado e relativamente indiferenciado, uma comunidade ou mesmo comunhão de indivíduos iguais que se submetem em conjunto à autoridade geral dos anciãos rituais" (Turner, 2013, p. 99). Tais conceitos são pertinentes à análise do objeto estudado, uma vez que o caráter liminar e a communitas, como modalidade de interação social, evidenciam uma oposição (antiestrutura) em relação à estrutura hospitalar, o que abre possibilidades de conflito e transformação social.

O objetivo deste artigo foi interpretar as dimensões estruturais e simbólicas do espaço físico da copa, por meio das interações sociais entre os profissionais da equipe multiprofissional da Unidade de Trauma de um Hospital Universitário.

\section{METODOLOGIA}

A abordagem qualitativa foi a ferramenta para o desenvolvimento deste estudo, norteada pelo referencial teórico-metodológico da pesquisa etnográfica (Spradley, 1980; Spradley e McCurdy, 1979). A etnografia envolve um contínuo esforço de se colocar em encontros e eventos específicos, com vista à compreensão de contextos e fenômenos significativos para um dado grupo social. Dessa forma, ela combina o trabalho de campo e uma variedade de desenhos e métodos de pesquisa para produzir relatos, descrições, interpretações e representações da vida humana, histórica, política e biograficamente situadas (Tedlock, 2000).

\section{Cenário do estudo e atores da pesquisa}

O cenário cultural foi a Unidade de Trauma de um Hospital Universitário, situado na cidade de Campinas (SP). Trata-se de um hospital mantido com recursos do Sistema Único de Saúde e da Universidade. A unidade de trauma está vinculada ao Departamento de Cirurgia da Faculdade de Ciências Médicas da Universidade. Em geral, os pacientes admitidos na unidade de trauma são submetidos a tratamento cirúrgico de urgência ou eletivo, em diversas especialidades.

A equipe multiprofissional estava dividida em três turnos de trabalho: o plantão da manhã (7 às 13h), o plantão da tarde (13 às 19h) e o plantão noturno (19 às 7h). A carga horária de trabalho semanal variava entre 30 e 40 
horas, a depender da categoria profissional. Em cada plantão trabalhavam um médico $\mathrm{R}_{1}$ (aluno do $1^{\circ}$ ano do Programa de Residência Médica em Cirurgia do Trauma. Ele era apoiado pelos residentes mais graduados, $\mathrm{R}_{2}$ e $\mathrm{R}_{3}$, e pelo docente responsável), dois enfermeiros assistenciais, um enfermeiro supervisor, quatro técnicos de enfermagem, um fisioterapeuta, um assistente social e um agente administrativo.

A unidade de trauma estava dividida em sete quartos, um deles com quatro leitos e os demais com dois. Do total de leitos, quatro eram destinados a pacientes em cuidados intensivos ou semi-intensivos.

A copa compreendia um espaço de, aproximadamente, três metros de comprimento por dois metros de largura. Situava-se em frente a dois quartos de pacientes. Em seu interior encontravam-se dispostos alguns móveis (geladeira, mesa, cadeiras, armários) e eletrodomésticos, além da pia para preparo de alimentos, bebidas e lavagem das mãos e utensílios. Cada plantão tinha seu espaço no armário onde eram guardados os ingredientes necessários para o preparo do café e os utensílios domésticos de que faziam uso.

$\mathrm{O}$ acesso à copa era livre. Oficialmente cada funcionário tinha o direito de estar na copa por 15 minutos durante um plantão de seis horas. É o tempo que lhes eram conferidos para descanso. Em cada plantão, o funcionamento da copa tinha início juntamente com as atividades do processo de trabalho. Realizadas as atividades iniciais do plantão, o responsável pelo café dirigia-se à copa, reunia os ingredientes e preparava a primeira garrafa de café.
No decorrer do plantão, várias eram preparadas. Esta era uma das atividades primordiais na copa, pois o café é o desencadeador de situações sociais. Passadas as primeiras duas ou três horas do plantão, tinha início o "horário de pico" na copa. Esse "horário de pico"1 durava, em média, uma hora devido aos revezamentos que os atores sociais realizavam.

$\mathrm{Na}$ condução do trabalho de campo, foram considerados informantes gerais aqueles indivíduos que estiveram presentes nas cenas culturais observadas. Esses atores foram os profissionais da equipe multiprofissional e pacientes da unidade de trauma, os quais participaram da pesquisa por meio da observação participante. No diário de campo foram mantidos registros etnográficos de todas as informações que contribuíram para documentar a situação social em estudo.

Os informantes-chave foram selecionados entre os membros da equipe multiprofissional, mediante os seguintes critérios: possuir vínculo empregatício com a Instituição; trabalhar nos plantões manhã ou tarde; e estar presente durante o período de coleta de dados. Os critérios para exclusão da pesquisa foram: não possuir vínculo empregatício com a Instituição (estudantes e residentes) e estar de férias ou em licenças diversas durante o trabalho de campo.

Como informantes gerais tiveram-se 45 profissionais, sendo: 20 técnicos de enfermagem, 12 enfermeiros, 06 médicos residentes, 03 técnicos administrativos, 02 fisioterapeutas, 01 nutricionista e 01 assistente social. Desse total, 18 participaram como informantes-chave e foram entrevistados individualmente, sendo: 08

\footnotetext{
${ }^{1}$ O "horário de pico", segundo os informantes, diz respeito ao horário em que todos costumam ir à copa para tomar café, lanchar e conversar. Ou seja, a expressão "pico" diz respeito ao período de maior movimento de pessoas naquele espaço. Em geral, esse horário é no meio do período de cada plantão. Assim como no trânsito das grandes cidades, o "horário de pico" na copa era caracterizado pelo fluxo intenso de pessoas no interior da copa e pelos burburinhos de suas conversas e risadas. Nos horários "entrepicos" os profissionais também frequentavam-na, mas em duplas ou em pequenos grupos e, geralmente, para conversas particulares.
} 
enfermeiros, 06 técnicos de enfermagem, 01 fisioterapeuta, 02 técnicos administrativos e 01 assistente social que atenderam aos critérios de inclusão do estudo.

\section{Trabalho de campo, análise das informações e aspectos éticos}

As informações foram coletadas por meio da observação participante e da entrevista semiestruturada, perfazendo seis meses de trabalho de campo. Os dados sóciodemográficos dos profissionais (sexo, idade, cor/raça, estado civil, escolaridade, ocupação, locais de trabalho, renda familiar, jornada de trabalho, tempo de trabalho na instituição) foram obtidos por meio de questionário estruturado.

A observação participante iniciou com observações descritivas, a fim de obter um panorama geral da situação, seguindo-se as focadas, conforme foram delimitados os domínios culturais. Essa técnica foi útil na descrição do cenário cultural, além da verificação de hipóteses ou afirmações, complementação dos dados e para a interpretação do que foi dito pelos profissionais nas entrevistas.

Para as entrevistas semiestruturadas foram feitos convites aos informantes-chave e agendado um horário de acordo com a disponibilidade de tempo de cada um deles. As entrevistas tiveram início com questões descritivas de acordo com o roteiro elaborado, seguidas das questões estruturais. Todas as entrevistas foram realizadas na sala da supervisão de enfermagem da unidade de trauma, registradas em áudio e utilizadas para a compreensão do contexto sóciocultural e do ponto de vista dos profissionais. Nos verbatins extraídos do corpus das entrevistas os informantes são identificados por códigos (P1, P2...): onde a letra "P" significa "profissional" e o número corresponde à ordem de aparecimento no texto.
Analisaram-se as informações de forma concomitante à coleta. Os domínios culturais foram buscados nos registros etnográficos a partir da identificação das relações semânticas e dos termos cobertos e incluídos. Após a elaboração dos domínios hipotéticos, os mesmos foram testados por meio de observações e entrevistas, utilizando questões estruturais (Spradley, 1980).

As taxonomias foram estruturadas a partir dos domínios mais significativos, com maior quantidade de informações e que permitiram a interpretação do significado atribuído pelos profissionais às interações sociais na sala do café. A análise taxonômica iniciou a partir da seleção de um domínio significativo com maior quantidade de termos incluídos, buscando identificar novos termos, as relações e as subdivisões dos mesmos nos registros etnográficos. Então foi construída uma tentativa de taxonomia em forma esquemática e a mesma foi elucidada e checada com os informantes, a partir de observações focadas e entrevistas com questões estruturais e seletivas (Spradley, 1980).

$\mathrm{Na}$ etapa da análise temática identificou-se a grande unidade de pensamento presente nos domínios e que oferecia uma visão holística das cenas culturais. Assim, o tema cultural constituiu o padrão maior em torno do qual se incorporaram as relações entre os domínios identificados (Spradley, 1980). O processo cíclico de coleta e análise de dados foi interrompido quando se obteve a circularidade das informações e os domínios mais significativos do estudo contiveram informações suficientes para emergir o tema cultural. O projeto de pesquisa foi encaminhado ao Comitê de Ética da Faculdade de Ciências Médicas da Universidade Estadual de Campinas e aprovado no Parecer $n^{\circ} 555 / 2008$. Foram respeitados os 


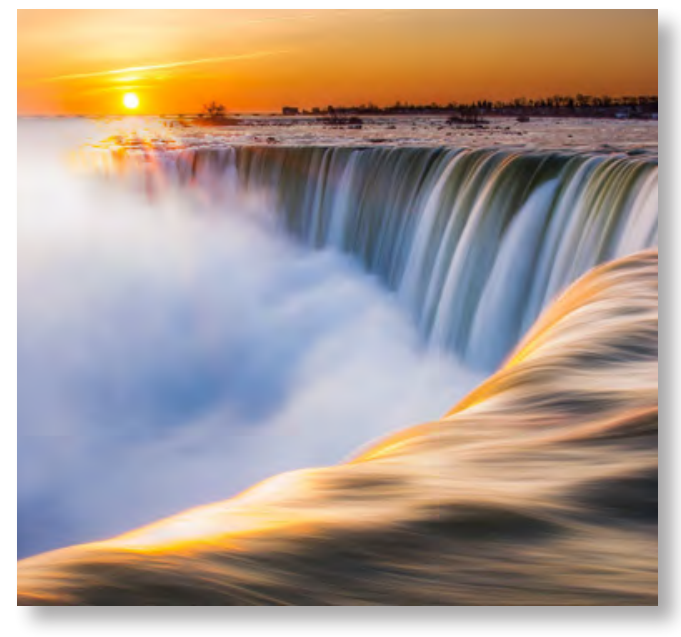

preceitos éticos de participação voluntária e consentida, segundo a Resolução 196/96 do Ministério da Saúde.

\section{RESULTADOS E DISCUSSÃO}

\section{Características de identificação}

Dos 45 participantes $62 \%$ eram do sexo feminino, com idade entre 23 e 57 anos, 46,7\% solteiros, $48,8 \%$ com renda familiar entre $\mathrm{R} \$ 2$ mil e R $\$ 4$ mil reais, 75\% possuíam dois vínculos empregatícios, 51,1\% trabalhavam 6 horas por dia e $29 \%$ faziam jornadas de 12 horas diárias. O tempo de experiência na enfermaria variou de 4 meses a 30 anos.

Da análise do material etnográfico emergiram quatro domínios e taxonomias culturais e um tema cultural, os quais são apresentados a seguir.

\section{Domínio cultural 1 - O estado liminar e a communitas}

Segundo os informantes, os motivos para ir à copa são os mais diversos:

"Vou à copa, primeiramente, para tomar um cafezinho. Mas o grande valor da copa é esse momento de você respirar um pouco, desabafar, sabe? Você desacelerar o coração. Se você ficar nessa correria aí, fica louco! Aí você chega lá, senta, toma um [respirou profundo em alusão a um fôlego], conta até 10, até 20, depois você anima de novo e vai... É onde você recupera a energia" (P1)!

"Vou à copa porque lá é o nosso ponto de encontro! Sentamos, conversamos, perguntamos como foi o dia, como está a enfermaria, como estão os pacientes. Conversamos coisas que no corredor não dá para parar e conversar, porque não dá tempo" (P2).

A sociabilidade promovida no interior da copa, além de englobar as funções mais atreladas ao lazer, faziam-se, principalmente, por meio da possibilidade de desvinculação da postura técnica em função de uma postura mais "pessoalizada" - próximo do que se é fora do hospital.

Tal desvinculação emergia como fundamental, por ser o "pré-requisito" para o tipo de sociabilidade vivenciada na copa (communitas). É como se fosse improvável estarem lá, sentirem e fazerem o que relatavam, estando distantes de uma postura ambígua (liminar), que lhes oferecesse a possibilidade de criar, de se colocarem em um espaço que contrariava a estrutura e a classificação próprias do ambiente hospitalar (antiestrutura).

Com isso, a copa adquiria os atributos de um espaço liminar no sentido de permitir aos ali presentes viverem um estado de margem e de ambiguidade (Van Gennep, 2008). Esse estado é denominado de liminaridade e sua relevância consiste em engendrar uma ambiguidade classificatória (Turner, 2005; Turner, 2013; Van Gennep, 2008; Douglas, 2010). Tal ideia fazia sentido para o contexto estudado por se tratar de um ambiente fortemente hierarquizado, estruturado e disciplinado (o hospital moderno).

Esse processo de liminaridade é, fundamentalmente, uma forte e singular coletiviza- 
ção, marcada pelo contato com o "nós essencial”, uma das dimensões mais importantes na constituição de um estado "antiestrutural”, um estado destituído de individualidade e compartimentalização (Turner, 2013). No entanto, cumpre ressaltar que a sociedade brasileira se caracteriza por seus valores hierárquicos e a evidente distinção entre o código da "casa" (fundado na família, na amizade, na lealdade, na pessoa e no compadrio) e o da "rua" (baseado em leis universais, na burocracia, no formalismo jurídico-legal). Nessa perspectiva, a liminaridade promoveria uma experiência com um "eu essencial" (DaMatta, 1997; 2000).

Nesse sentido, pode-se afirmar que os frequentadores da copa realizavam os dois processos descritos anteriormente: o "eu essencial", descrito por DaMatta $(1997 ; 2000)$ e o “nós essencial”, apontado por Turner (2013). Faziam-no da seguinte forma: primeiramente, os atores sociais entravam em contato com o "eu essencial", pois o trabalho no hospital tende a massificar comportamentos e padronizar processos de trabalhos. Diante disso, o ato de passar pela porta da copa e penetrar seu recinto permitia ao indivíduo um movimento simbólico de reencontro com seu "eu" fragmentado no processo de trabalho em saúde. Quando atingiam o "eu essencial" os atores sociais mobilizavam-se para a communitas, um modelo de correlacionamento humano e de sociabilidade, justaposto e alternante com o sistema estrutural, que é o processo de coletivização ou o "nós essencial” (Turner, 2013). A situação de communitas é um estado desprovido de individualidade e fragmentação, fortemente marcado pelo vínculo de comunhão entre os indivíduos iguais. Esse processo pode ser mais bem observado no trecho que segue:

"Na copa é outra postura! Dentro do quarto tem que ser mais séria, tem que ter uma pos- tura da enfermeira, da cuidadora. Dentro da copa você já pode ser mais você. Mostrar-nos um pouco mais, ser mais verdadeiros! Se fossemos comparar a enfermaria com um teatro, os profissionais seriam atores, os pacientes e os familiares seriam a platéia, os corredores e os quartos seriam os palcos e a copa seria os bastidores! Já comparando essa copa com a nossa casa, talvez a copa fosse o banheiro! [risos] Lá fazemos coisas que você não tem coragem de fazer na frente da sua família [risos]" (P3).

A partir do momento em que esse estado de communitas e, consequentemente, de antiestrutura se evidenciavam, o "nós essencial" passava a constituir o húmus social necessário para a construção de sociabilidades distintas às que são engendradas fora do espaço físico da copa.

No entanto, é fundamental lembrar que a communitas e antiestrutura vivenciadas na copa guardavam certo grau de parcialidade. Esse fato podia ser observado, por exemplo, na existência de mitos de interdição a pacientes e estudantes e de padrões de comportamentos que, embora não fossem tácitos, tornavam o acesso à copa "privilégio" de alguns. Ou seja, a communitas e a antiestrutura experimentadas na copa eram verdadeiras e radicais quando comparadas à estrutura rígida do hospital, mas parcial e flexível quando analisadas isoladamente.

\section{Domínio cultural 2 - A significação das in- terações sociais na realidade externa à copa}

Tendo como ponto de referência a sala do café, observou-se que, em termos de espacialidade, o universo social da unidade de trauma estava simbolicamente dividido da seguinte forma: o espaço interno da copa (liminar) e o espaço externo a ela (compreendia os demais espaços físicos: posto de enfermagem, quartos 
de pacientes, corredores, etc.). Dessa maneira, as interações sociais engendradas no interior da copa possuíam usos sociais e significados diversos na realidade externa. Para os profissionais em geral, as interações sociais ocorridas na copa permitiam o manejo da convivência com o colega de trabalho. Lá existia um sentido de coletividade, mas, ao mesmo tempo, servia como "banco de dados", objetivos e subjetivos, na medida em que fomentava a compreensão das relações que se davam fora dela. Com as informações partilhadas nos "horários de pico", a informação circulava intencionalmente em todas as direções e, às vezes, endereçada, o que permitia conhecer o outro e assim negociar, no cotidiano, as relações de convivialidade. Por isso, as interações sociais na copa não eram ingênuas:

"A copa é um lugar que usamos para desabafar e é, também, o lugar onde julgamos: julgamos as ações que foram feitas, quando alguém mal-trata, quando alguém faz algo que não estamos de acordo. É onde começa o comentário de tudo, para que os colegas que chegarem perto das pessoas citadas, já chegarem com mais jeito e saberem como é a situação" (P4).

Além disso, tais interações não se prestavam apenas para o desabafo, pelo contrário, o que ocorria na copa ganhava vida fora dela:

"Lá você conhece mais as pessoas: o que acham, o que falam, quem faltou, quem deu atestado. É um momento social! E, como enfermeiro, não deixamos de analisar as pessoas, nunca. Às vezes, em um discurso, em um descuidado sobre o que fez no final de semana $e$ comportamentos com amigos, você começa a imaginar como a pessoa pode ser profissionalmente e, também, como amigo. Não dá para negar que há isso. Não que você use tudo isso diretamente durante o trabalho, mas são informações que você capta" (P5).
Por outro lado, para os dirigentes da unidade de trauma, a copa despontava como um motivo de constante preocupação, pois figurava como um espaço liminar, que produzia communitas e antiestrutura. Nesse sentido, ela representava uma perturbação da norma, uma fuga ou esconderijo, como expressou alguns informantes. Diante disso, pergunta-se o porquê de em quase toda parte se atribuir às situações e papéis liminares propriedades mágico-religiosas (no caso em estudo, referem-se à possibilidade de serem contrárias aos modelos, rotinas, por deixar as pessoas distantes dos “olhos" disciplinadores), ou perigosas, de mau agouro, contaminadoras para as pessoas, os objetos, os acontecimentos e relações que não foram ritualmente incorporadas ao contexto liminar (Turner, 2013).

Em resumo, na perspectiva daqueles aos quais incumbe a manutenção da "estrutura", todas as manifestações continuadas da communitas devem aparecer como perigosas e anárquicas, e precisam ser rodeadas por prescrições, proibições e condições. É como se aquilo que não pode, com clareza, ser enquadrado nos critérios tradicionais de classificação, ou se situa entre fronteiras classificatórias, fosse considerado "contaminador" e "perigoso" (Douglas, 2010; Turner, 2013).

"Uma situação desagradável que me marcou muito foi quando o pessoal [supervisores e diretores] quiseram proibir que a dupla de técnicos de enfermagem fosse junta à copa. Na verdade, é proibido, até hoje, mas ninguém respeita! Eu achei um absurdo quando eles fizeram isso! Eles quiseram tirar isso de nós [silêncio]" (P6).

"A copa tem pontos positivos e negativos. Os positivos é que você acaba interagindo mais com a equipe e o ambiente fica melhor de se trabalhar! Só que, na copa, você tem que ter o seu momento e saber até onde dá para continuar 


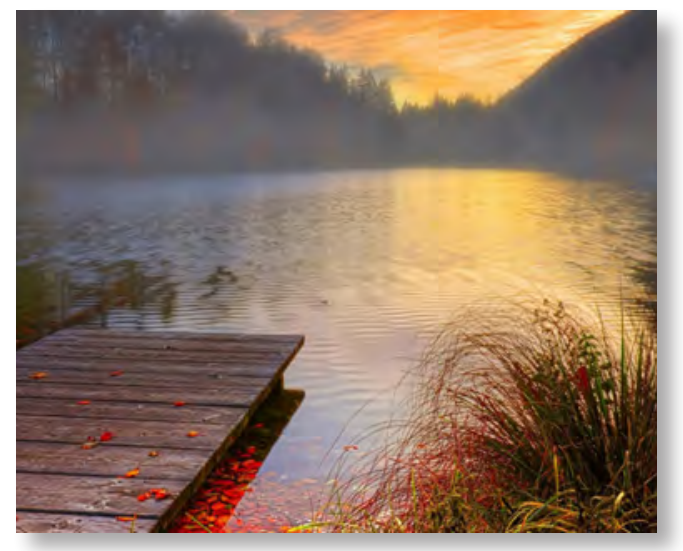

ali. tem hora que se você não souber viver lá, você se prejudica" (P7).

Baseado nessas afirmativas pode-se observar uma tensão entre a estrutura própria da instituição hospitalar e a communitas e antiestrutura vivenciadas na copa. Essa tensão dava origem, geralmente, a proibições diversas, à vigilância dos frequentadores, a sanções leves para quem exagerava na maneira de utilizar a copa, e, geralmente, recaía sobre os profissionais de nível médio.

\section{Domínio cultural 3 - O significado da porta fechada}

No contexto estudado, o ato de atravessar a porta significava ultrapassar o limite entre o mundo externo (que corresponde ao mundo estruturado do hospital) e o mundo liminar da copa. Assim, ao atravessar a soleira, o indivíduo ingressava em um ambiente novo, diferente, liminar (Van Gennep, 2008). O cuidado em manter a porta fechada referia-se, primeiramente, ao fato de ser uma communitas parcial ou relativa e também ao meticuloso trabalho, que requer esforço e destreza dos atores sociais, para manter a impressão que eles veiculavam fora dali para seus pacientes, acompanhantes e para eles mesmos, no sentido de não afetarem a eficácia de suas representações (práticas profissionais) diante da platéia.
O recurso que a manutenção da porta da copa fechada simbolizava era fundamental nesse dilema, já que o elemento ocasionador do caos e da descrença no papel social e na impressão de realidade criada e representada por eles era o confronto (para a platéia, notadamente, e para eles próprios) entre um contexto estrutural (o hospital e seus papéis profissionais) e um espaço de antiestrutura (a copa) (Goffman, 1989).

"Eu acho que os pacientes e familiares percebem a copa negativamente! Para evitar que isso aconteça, temos uma regra: entrou, fechou a porta! [risos] A porta sempre fica fechada porque lá dentro é aquela coisa dos bastidores: ninguém pode ver! Porque eles iriam nos achar diferentes, com certeza" (P3).

Para os profissionais, a coerência se perderia nesse embate, no momento em que os padrões de decoro, defendidos pela instituição e incorporados por eles em suas representações, não estariam em vigor na copa - um ambiente no qual o sistema social estruturado da organização era desmontado e seus elementos ressignificados.

"Penso que isso afete nossa imagem como profissionais porque os pacientes não nos conhecem, não sabem da nossa qualidade como profissionais. Você deve procurar passar confiança, credibilidade, seriedade naquilo que está fazendo. Porque se você tem comportamento diferente disso, as pessoas confiam menos em você. Acho que isso pode gerar uma desconfiança da competência de algumas pessoas que se comportam de forma diferente" (P8).

Para além dos recursos de manutenção da representação de suas práticas profissionais, esses discursos também remetem aos já citados mitos de interdição relacionados à permissão de acesso das pessoas à copa. No tocante aos pacientes e familiares, destacam-se duas 
razões que, segundo os informantes, justificavam a interdição do acesso à copa. Como se tratava de um espaço no qual havia rituais de comensalidade, o cuidado em evitar a presença de pacientes na copa se devia ao fato de lá existirem alimentos "proibidos" para alguns deles: os diabéticos ou os que estão em jejum, por exemplo.

"A porta fica sempre fechada porque têm quartos na frente da copa, tem paciente que está em jejum e se ficarmos comendo com a porta aberta é chato para eles! E também porque lá dentro, não deixamos de ser uma equipe, mas ali somos pessoas normais e aqui fora somos profissionais" (P9).

Além disso, para os profissionais, a copa se caracterizava como um contexto de "fuga" das situações de trabalho que envolviam dor e sofrimento para pacientes e familiares. Portanto, a presença de pacientes e acompanhantes que vivenciavam tais situações poderia trazer aquilo que se queria, pelo menos no momento em que se estava na copa, manter distante.

\section{Domínio cultural 4 - O compartilhar de ex- periências na copa}

No interior do hospital, a sociabilidade na copa reproduzia muito daquilo que os profissionais não podiam vivenciar no mundo externo ao ambiente de trabalho e do lar, devido aos seus compromissos profissionais. $\mathrm{O}$ que mais chamou atenção no trabalho de campo era a capacidade dos sujeitos envolvidos construírem e vivenciarem uma situação que, em muito, se aproximava à experiência do expectador de um filme no cinema.

No cinema, o corpo do espectador encontra-se, geralmente, entregue à poltrona, ao silêncio, à escuridão. A estrutura espacial do ambiente o impele ao mergulho na tela de luz. Qualquer ruído ou visão fora da tela remete o espectador à existência da realidade externa, o que o faz despertar para a presença do cotidiano, comprometendo o estado psicológico necessário à adesão ao mundo do filme. O espectador, na verdade, não "assiste" ao filme, ele o vivencia de uma maneira tão próxima do sonho e, numa total intensidade, que não raro ele próprio se surpreende gritando, xingando, torcendo ou transpirando de emoção. O espectador desprende-se da poltrona, entra na tela e desfruta a vida emprestada pela personagem e se converte em protagonista do jogo simulado de eventos (Fernandes, 2007).

De maneira similar, o contexto de liminaridade, communitas e antiestrutura da copa, liberava os indivíduos em busca de estados que os remetiam a dimensões de realidades que se distanciavam da tentativa de compreendê-las ou interpretá-las.

"A copa para mim é um refúgio. Ela é incrivel! Você entra, fecha a porta, parece que você saiu da enfermaria. Então você descansa um pouco quando o plantão está complicado. Você relaxa um pouco! Come alguma coisa, conversa com os outros funcionários, às vezes não conversa, fica um tempo sem trabalhar, colocamos algumas coisas em dia. É um refúgio mesmo" (P10).

Essa "situação cinema” (Mauerhofer, 1949) pode ser considerada como a mais próxima da "situação copa”. Nesta última, o indivíduo conseguia "reproduzir" sensações, circunstâncias e tudo o mais que se passa (ou passou) em realidades opostas e, às vezes, conflitantes à que, realmente, estava inserido naquele momento. Eram nesses "desprendimentos de poltronas" que eles faziam e eram o que, temporariamente, estavam interditados de fazerem ou não era conveniente fazer - um fato que se aproximava de uma das características de instituição total: a segregação entre o mundo externo e o mundo da instituição (Goffman, 2005). 
"Nós saímos de casa para trabalhar e ficamos o dia inteiro fora. Então aonde você vai conversar? Não somos de ferro! Você acaba falando com os amigos aqui, desabafando, chorando, contando problemas, até pessoais! Tem sempre alguém com quem nos identificamos e acabamos conversando. É bem isso, o que você não pode fazer fora daqui, acaba fazendo lá dentro" (P11).

Nesse sentido, a sociabilidade na copa promovia o compartilhamento de experiências ligadas a aspectos gerais de suas vidas, além dos enquadramentos operados pelo mundo do trabalho. Mais uma vez, o caráter liminar desse espaço possibilitava assumir posições que religavam os universos pessoais (fora do trabalho) e os universos profissionais. Dessa forma, a copa e as interações sociais lá engendradas favoreciam a própria ressignificação da experiência de ser trabalhador em saúde, por meio, principalmente, do resgate de dimensões mais humanas e pessoalizadas das relações sociais.

\section{Tema cultural - "A copa é o lugar que serve para tudo!": espaço, liminaridade e sociabi- lidade}

Os domínios culturais apresentados desvelaram a existência de uma ordem espacial e simbólica própria ao contexto estudado. Tal ordem nos remete ao papel fundamental dos espaços na arquitetura do hospital moderno, uma vez que no processo de disciplinarização do hospital, seus espaços foram medicalizados em sua função e em seus efeitos (Foucault, 1979).

Em toda unidade hospitalar há um ordenamento dos espaços de acordo com as funções e atividades neles desempenhadas. Trata-se, pois, de uma "localização funcional" e de um "quadriculamento" da estrutura física como um dispositivo de poder disciplinar e de sua anátomopolítica do detalhe. Ou seja, por meio do controle dos espaços se cria, igualmente, estratégias de governo dos corpos (Foucault, 2010).

Essa ordem espacial e simbólica se compõe de fragmentações, oposições, funcionalidades e significações. Por isso, tal ordem demarca a separação entre o mundo interno à instituição e o mundo externo, tanto para os profissionais quanto para os pacientes; o que acentua as representações de papéis sociais diversos (papel de doente, papel de enfermeiro, papel de médico, etc.), as classificações, as hierarquias, as táticas disciplinares.

Mas, se por um lado, o estabelecimento de uma ordem espacial organiza e orienta as relações sociais na unidade de trauma e o andamento do processo de trabalho em saúde; por outro, ela introduz descontinuidades no espaço físico da unidade, na medida em que há locais mais significativos no processo de trabalho (como o posto de enfermagem e os quartos de pacientes) que outros (como o expurgo e a sala do café). Tais descontinuidades atuam na anatomia política que caracteriza a arquitetura do hospital, e, se são produzidas pela própria organização do trabalho em saúde, têm seus efeitos ampliados pelas relações dos grupos humanos que atuam nesse contexto (profissionais, pacientes, familiares, estudantes, docentes, etc.).

É no interior dessa ordem espacial e simbólica que o espaço físico da copa e as interações sociais que nele se engendram alteram a economia de significações posta em operação pela ordem que se pretende hegemônica e pelo poder e discurso institucionais. Como bastidor de um grande cenário (portanto, de pouca significância no processo de trabalho), a copa, com seus tabus, atributos liminares e mitos de interdição, possibilita aos que a frequenta inverter a ordem espacial e estabelecer a communitas no contexto estrutural da unidade de 
trauma, em particular, e, mais amplamente, no hospital.

Esse processo simbólico coloca em relações de oscilação e, no caso deste estudo, também, de oposição, diferentes níveis de realidade: um nível sociológico (as relações profissionais no hospital versus as relações pessoais fora do hospital), um nível grupal (as relações entre a equipe multiprofissional e os pacientes e familiares) e um nível individual (as relações entre o profissional de saúde e a equipe multiprofissional) (Andrés Ludueña, 2006). A estes três níveis de realidade acrescentamos um nível microssociológico que se refere às relações entre os códigos e interações sociais existente na copa e fora dela.

Portanto, era nesse contexto relacional experimentado na copa que os informantes se tornavam entidades liminares e, por meio do modo de interação social próprio do estado liminar, a communitas, decompunham as fragmentações, as oposições, as funcionalidades e as significações estabelecidas pela ordem espacial hegemônica. Nesse sentido, o espaço físico da copa era ressiginificado pela ação e criatividade dos sujeitos e passava a desempenhar um espaço comunicacional, relativamente indiferenciado, rudimentarmente estruturado e com indivíduos iguais - típico da communitas - que influencia, em última instância, a sociabilidade entre os informantes dentro e fora da copa.

\section{CONSIDERAÇÕES FINAIS}

Conforme evidenciado neste estudo etnográfico, o impacto das relações existentes entre espaço, liminaridade e sociabilidade nas interações sociais engendradas na copa da unidade de trauma é fortemente sentido no processo de trabalho em saúde.

Por meio das relações de sociabilidade vivenciadas na copa, os profissionais ressigini- ficam suas experiências de trabalhadores em saúde. Ao resistirem à tendência planificadora e homogeneizante que os hospitais tendem a imprimir em suas unidades, os profissionais, juntamente com os pacientes, familiares e estudantes, resgatam dimensões mais profundas e, consequentemente, humanas das relações sociais no trabalho. Tal resgate transforma o ambiente artificial, quadriculado, funcional, hierarquizado e estruturado da unidade em uma atmosfera que amplifica as subjetividades em interrelação, retoma aspectos perdidos pela racionalização e objetivação das práticas profissionais, e considera o indivíduo em uma perspectiva inovadora que integra suas variadas interfaces e conflitos.

A existência de espaços físicos, no interior do hospital, para a sociabilidade dos profissionais afirma-se como fundamental para a condução do processo de trabalho e para a qualidade de vida do trabalhador. Por isso, recomenda-se que na implementação de políticas públicas e estratégias de gestão do processo de trabalho, sobretudo no contexto estudado, leve-se em consideração a experiência e a simbologia de espaços que proporcionem um sentido de reflexividade e dialogicidade que dificilmente encontra oportunidade para se manifestar no hospital - a copa pode ser apenas um deles!

\section{BIBLIOGRAFÍA}

- Andrés Ludueña, G. (2006) Etnografía del espacio en monasterios de clausura en Argentina. In: Wilde, G.; Schamber, P (compiladores) Simbolismo, ritual y performance. SB, Buenos Aires:121-55.

- DaMatta, R. (1997) A casa \& a rua: espaço, cidadania, mulher e morte no Brasil. 5 ed. Rocco, Rio de Janeiro.

- DaMatta, R. (2000) Individualidade e liminaridade: considerações sobre os ritos de passagem e a modernidade. MANA, 6 (1), 7-29. 
- Douglas, M. (2010) Pureza e perigo. 2 ed. Perspectiva, São Paulo. (Debates; 120).

- Fernandes, A.L.S. Cinema e psicanálise [página na internet]. [acesso em 2007 Out 16]. Disponível em: http:// cbp.org.br/rev2807.htm.

- Foucault, M. (1979) Microfísica do poder. Graal, Rio de Janeiro.

- Foucault, M. (2010) Vigiar e punir: história da violência nas prisões. $38^{\mathrm{a}}$ ed. Vozes, Petrópolis.

- Goffman, E. (1989) A representação do eu na vida cotidiana. Vozes, Petrópolis.

- Goffman, E. (2005) Manicômios, prisões e conventos. Perspectiva, São Paulo. (Debates; 91).

- Luz, M.T. (1986) As instituições médicas no Brasil: instituição e estratégia de hegemonia. 3 ed. Graal, Rio de Janeiro.

- Mauerhofer, H. (1949) Psychology of film experience. Penguin Film Review, 8.
- Sahlins, M. (2003) Cultura e razão prática. Jorge Zahar Editor, Rio de Janeiro.

- Spradley, J.P. (1980) The participant observation. Holt, Rinehart, and Winston, Orlando (US).

- Spradley, J.P.; McCurdy, D.W. (1979) The ethnographic interview. Holt, Rinehart, and Winston, New York (US.

- Tedlock, B. (2000) Ethnography and ethnographic representation. In: Denzin, N.K.; Lincoln, Y.S. (editors). Handbook of qualitative research. 2nd ed. Sage, Thousand Oaks: 455-86.

- Turner, V.W. (2005) Floresta de símbolos: aspectos do ritual Ndembu. Editora da Universidade Federal Fluminense, Niterói.

- Turner, V.W. (2013) O processo ritual: estrutura e antiestrutura. 2 ed. Vozes, Petrópolis.

- Van Gennep, A. (2008) Los ritos de paso. Alianza Editorial, Madrid.

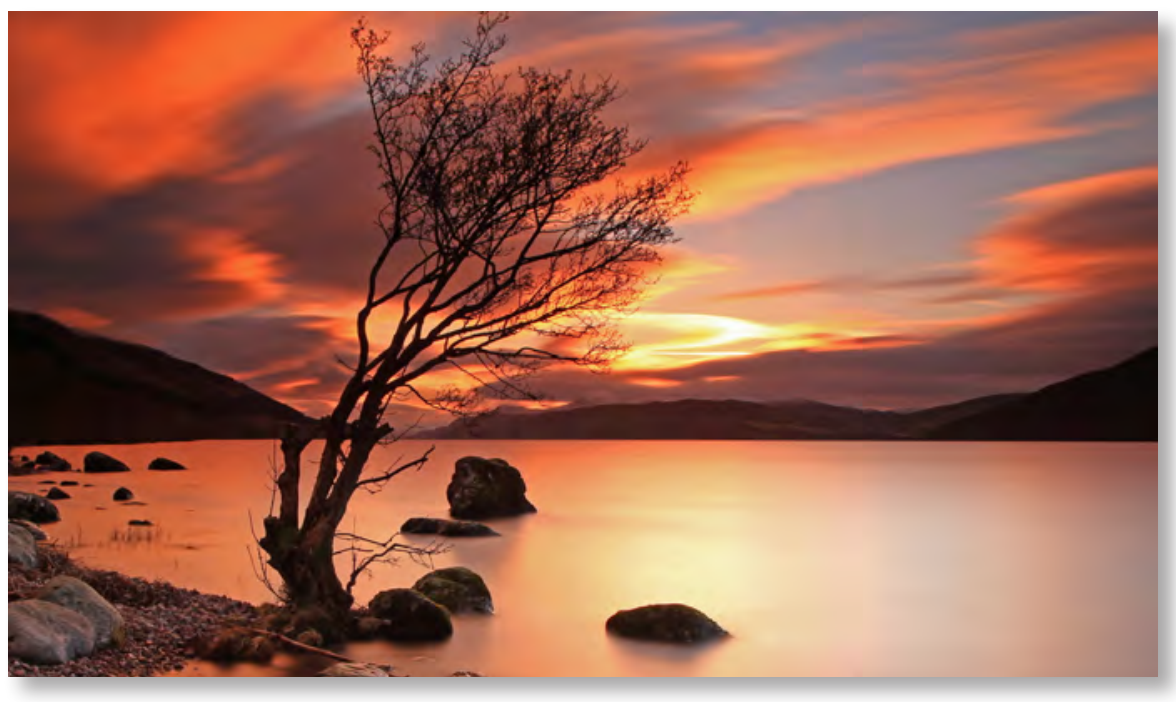

